\title{
Efficacy of selected oral chemotherapeutants against Ichthyophthirius multifiliis (Ciliophora: Ophyroglenidae) infecting rainbow trout Oncorhynchus mykiss
}

\author{
Andrew P. Shinn*, Rodney Wootten, Isabelle Côté, Christina Sommerville \\ Institute of Aquaculture, University of Stirling, Stirling FK9 4LA, United Kingdom
}

\begin{abstract}
The chemotherapeutic efficacy of 6 in-feed compounds against Ichthyophthirius multifiliis Fouquet, 1876 was assessed using experimental infections of rainbow trout Oncorhynchus mykiss (Walbaum) fingerlings. Trial doses of $104 \mathrm{ppm}$ amprolium hydrochloride or $65 \mathrm{ppm}$ clopidol fed to fish for $10 \mathrm{~d}$ prior to infection significantly reduced the number of trophonts establishing in trout fingerlings by 62.0 and $35.2 \%$ respectively. In-feed treatments of infected trout with either 63 or $75 \mathrm{ppm}$ amprolium hydrochloride, $92 \mathrm{ppm}$ clopidol, or 38, 43 or $47 \mathrm{ppm}$ salinomycin sodium for $10 \mathrm{~d}$ also significantly reduced the number of surviving trophonts by 77.6 and $32.2 \%$ for amprolium, $20.1 \%$ for clopidol and $80.2,71.9$ and $93.3 \%$ respectively for salinomycin sodium.
\end{abstract}

KEY WORDS: Ichthyophthirius multifiliis · Whitespot · Amprolium · Salinomycin sodium · Clopidol · Oncorhynchus mykiss

\section{INTRODUCTION}

The holotrichous ciliate Ichthyophthirius multifiliis Fouquet, 1876 is regarded as one of the most pathogenic diseases of freshwater fishes (Matthews 1994). Infections in farmed fishes are common (Valtonen \& Keranen 1981), but epizootics do occasionally occur in wild fishes (e.g. Traxler et al. 1998). Within the UK, the British Trout Association has estimated that losses to the trout industry were in the region of $5 \%$ of infected batches with losses of between 30 and $80 \%$ in certain cases and with ca. $30 \%$ of British trout farms affected by I. multifiliis.

Of the chemicals that were once commonly used against ichthyophthiriasis in food fishes, such as the rainbow trout Oncorhynchus mykiss (Walbaum), the use of dimetridazole in food-producing animals has been banned by the European Commission because of its considered carcinogenicity to humans (Anonymous 1995), as has malachite green which is also suspected to be mutagenic. At present, only formalin and chlo-
ramine-T are permitted for use against Ichthyophthirius multifiliis in the European Union, and the activity of these chemicals is limited; they are effective only in killing the external stages of the parasite and multiple bath treatments are necessary for its control. Thus, there is a real need to find an efficacious in-feed treatment to replace dimetridazole and malachite green. For I. multifiliis, a parasite situated within the epithelium of the host, an in-feed treatment represents a more appropriate system of drug delivery. Before reaching their target, in-feed compounds are not compromised by environmental conditions (water solubility, activity diminished by organic loading, $\mathrm{pH}, \mathrm{O}_{2}$ etc.) to the same degree as bath treatments; they can have a longer window of activity, are less stressful to administer, and the by-products generated by the host tissues can be more efficacious than the parent compound. Infeed compounds, however, depend upon the host being sufficiently hungry to take the medicated diet. The efficacy of 6 in-feed anticoccidiostats, amprolium hydrochloride, clopidol, decoquinate, monensin, nicar- 
bazin and salinomycin sodium, against I. multifiliis were assessed (Table 1).

Although more commonly used as an anti-coccidial in lambs and in cattle, decoquinate has also been successfully used for the treatment of Hepatozoon americanum infection in dogs (MacIntire et al. 2001), and has been demonstrated to control ovine toxoplasmosis (Buxton et al. 1996). Amprolium, clopidol, monensin, nicarbazin and salinomycin sodium are all commonly used for the treatment of poultry infected with Eimeria spp. (Arakawa et al. 1991, Peeters et al. 1994, Daugschies et al. 1998). Monensin, salinomycin and nicarbazin have been used to completely inhibit the growth of Cryptosporidium parvum (Armson et al. 1999), and salinomycin sodium has been demonstrated to reduce the incidence of shedding of Salmonella enteritidis in broilers at 6 wk post-infection (Bolder et al. 1999) and to cause irreversible damage to the plasmodial developmental stages of Henneguya sp. (Dohle et al. 2002).

\section{MATERIALS AND METHODS}

Fish husbandry. To assess the efficacy of the various compounds, Oncorhynchus mykiss (Walbaum) with a mean weight of $6.5 \mathrm{~g}$ were obtained from a commercial hatchery and were acclimated in 501 flow-through tanks for 2 wk prior to the start of a treatment. The water supplied to the tanks was carbon-filtered and the temperature within the tanks was maintained at $15^{\circ} \mathrm{C}$. When the incoming water temperature dropped to a point at which it was no longer possible to heat tanks on a flow-through system and maintain a steady $15^{\circ} \mathrm{C}$, then static tanks were used. The trout were fed a commercial pelleted feed (Trouw Nutra Trout Fry 03) top-dressed with cod liver oil, at $1 \%$ body weight $\mathrm{d}^{-1}$. Those fish receiving medicated feed for a pre-determined period prior to theront exposure were identified by means of individual dye marks ( $1 \%$ alcian blue in distilled water) on the ventrum.

Ichthyophthirius multifiliis infection protocol. Tomonts of Ichthyophthirius multifiliis derived from brown trout Salmo trutta L. were obtained from R. A. Matthews, University of Plymouth, UK, and a culture was maintained in Oncorhynchus mykiss held in aquaria at the Institute of Aquaculture, University of Stirling. Mature trophonts were collected with a glass pipette as they exited their fish hosts, or were recovered from the bottom of plastic tanks containing infected stock fish. These tomonts were transferred to pre-rinsed plastic Petri dishes containing $50 \mathrm{ml}$ carbonfiltered, dechlorinated, $15^{\circ} \mathrm{C}$ water, and were main-

Table 1. Details of chemotherapeutants tested in this study

\begin{tabular}{|c|c|}
\hline Compound & Properties \\
\hline \multicolumn{2}{|c|}{ Amprolium hydrochloride } \\
\hline Synonym: & (1-[(4-amino-2-propyl-5-pyrimidinyl)-methyl]-2-methyl pyridinium chloride hydrochloride \\
\hline Chemical formula: & $\mathrm{C}_{14} \mathrm{H}_{19} \mathrm{~N}_{4}^{+} \mathrm{Cl}^{-} \mathrm{HCl}$ \\
\hline Activity: & Competes with thiamine active transport preventing coccidian merozoite production \\
\hline \multicolumn{2}{|l|}{ Clopidol } \\
\hline Synonym: & 3,5-dichloro-2,6-dimethyl-4-pyridinol \\
\hline Chemical formula: & $\mathrm{C}_{7} \mathrm{H}_{7} \mathrm{C}_{12} \mathrm{NO}$ \\
\hline Activity: & Prevents coccidian oocyst shedding \\
\hline \multicolumn{2}{|l|}{ Decoquinate } \\
\hline Synonym: & Ethyl-6-(decycloxy)-7-ethoxy-4-hydroxy-3-quinolinecarboxylate \\
\hline Activity: & Kills coccidia by interfering with cellular respiration \\
\hline \multicolumn{2}{|l|}{ Monensin } \\
\hline Synonym: & $\begin{array}{l}\text { 2-[5-ethyltetrahydro-5-[tetrahydro-3-methyl-5-[tetrahydro-6-hydroxy-6-(hydroxymethyl)-3,5- } \\
\text { dimethyl-2H-pyran-2-yl]-2-furyl-9-hydroxy-beta-methoxy-alpha, gamma, 2, 8-tetramethyl- 1, } \\
\text { 6-dioxaspiro[4.5]decane-7-butyric acid }\end{array}$ \\
\hline Chemical formula: & $\mathrm{C}_{36} \mathrm{H}_{61} \mathrm{O}_{11} \mathrm{Na}$ \\
\hline Activity: & $\begin{array}{l}\text { Renders membrane permeable to } \mathrm{Na}^{+} \text {and } \mathrm{K}^{+} \text {ions, allowing excess water into the cell (sporo- } \\
\text { zoite) and affecting mitochondrial activity }\end{array}$ \\
\hline \multicolumn{2}{|l|}{ Nicarbazin } \\
\hline Synonym: & Urea $\mathrm{N}, \mathrm{N}^{\prime}$-bis (4 nitrophenyl) compound with 4,6-dimethyl-2 (1H)-pyrimidinone \\
\hline Chemical formula: & $\mathrm{C}_{19} \mathrm{H}_{18} \mathrm{~N}_{6} \mathrm{O}_{6}$ \\
\hline Activity: & Acts at mitochondrial level, inhibiting energy metabolism \\
\hline \multicolumn{2}{|l|}{ Salinomycin sodium } \\
\hline Chemical formula: & $\mathrm{C}_{42} \mathrm{H}_{69} \mathrm{NaO}_{11}$ \\
\hline Activity: & Activity similar to that of monensin \\
\hline
\end{tabular}


tained in a $15^{\circ} \mathrm{C}$ incubator to the theront stage. To determine the number of theronts within each batch, $500 \mu \mathrm{l}$ of the theront culture was incubated for $5 \mathrm{~min}$ with $200 \mu \mathrm{l}$ of $0.01 \%$ neutral red stain before the addition of $300 \mu \mathrm{l} 10 \%$ buffered formalin. The number of viable theronts was determined with a $1 \mathrm{ml}$ Sedgewick-Rafter counting chamber on an Olympus BH2 compound microscope at $\times 40$. Groups of fish were infected together by the addition of ca. 2000 theronts per fish in static water for a minimum of $3 \mathrm{~h}$ in the dark (60 to 100 fish of $6.5 \mathrm{~g}$ each infected in $15 \mathrm{l}$ ). At the end of the theront exposure period, the water flow was restarted and the outflow rates for the tank adjusted; $24 \mathrm{~h}$ post-infection, fish were allocated to their respective experimental tanks.

In-feed trials. Once infected, 10 to 15 Oncorhynchus mykiss fingerlings were randomly allocated to each 101 tank and the appropriate chemotherapy regime was started. Trials comprised 3 experimental and 3 control replicates except where insufficient infective stages allowed the use of only 2 replicates. Fish were fed a $1 \%$ body weight ration of either a normal pelleted diet top-coated with $20 \mu \mathrm{l}$ cod liver oil or a medicated diet top-coated with $20 \mu \mathrm{l}$ cod liver oil for $10 \mathrm{~d}$ (Days 3 to 12 post-infection). Amprolium hydrochloride (Sigma), clopidol (Coyden 25, Rhone Merieux), decoquinate (Deccox, Rhone Merieux), monensin (Sigma), nicarbazin (Sigma) and salinomycin sodium (Sacox 120, Hoechst Roussel Vet) were incorporated into a pelleted feed at a nominal concentration of 100 ppm. The weight of the appropriate drug to be added was subtracted from the daily feed ration so that when the drug was added the total weight of drug and feed in each tank was the same. A $10 \mathrm{~d}$ feed supply, for each of the tanks in any given treatment, was made up at a time. Trout pellets and the drug were mixed in a plastic, lidded vessel and rotated for 20 min to ensure even coverage of the trout pellets with drug. At the end of each day, the feed ration for the next day was rotated to ensure even coverage, weighed out into a plastic vial (0.975 g for 15 fish of $6.5 \mathrm{~g}$ each) and $20 \mu \mathrm{l} \mathrm{cod} \mathrm{liver}$ oil was added. The vials were shaken, ensuring an even coverage of oil, and then left overnight to ensure absorption of the oil binding the drug to the pellets. The following day, the experimental fish were fed 2 rations: $75 \%$ in the first hour and the remainder $3 \mathrm{~h}$ later. Approximately $1 \mathrm{~h}$ after administering the second ration, the uneaten pellets were collected by siphon from the bottom of tanks. Uneaten pellets were dried and weighed and the percentage of food consumed was calculated.

Two treatment regimes were tested. Fish were either fed medicated feed for $10 \mathrm{~d}$ prior to infection (Expt 1) or fed medicated feed commencing 1 full day after infection with Ichthyophthirius multifliis (Expts 2 to 6). This established whether a compound could provide protection against stages of the parasite at anticipated periods of high infection or, administered immediately, could kill stages of the parasite in fish already infected. Experiments were terminated on Day 13 post-infection when the fish were killed by an overdose of $650 \mathrm{ppm}$ phenoxyethanol, and the total number of $I$. multifiliis trophonts on the excised gills and body surfaces were counted at $\times 4$ magnification using an Olympus SZ40 dissecting microscope.

Statistics. Trophont counts were subjected to normality (Anderson-Darling) and homogeneity of variance tests (F-test, Bartlett's, Levene's). If the conditions of normality were satisfied then parametric tests were applied (2-sample $t$-test, ANOVA, Tukey-Kramer multiple comparisons test). If the data were not normally distributed or the variances were heterogeneous, then non-parametric tests (Kruskal-Wallis, Dunn's, STP test, Mann-Whitney) were applied.

\section{RESULTS}

Trials in which the fish were given a $10 \mathrm{~d}$ treatment of either $100 \mathrm{ppm}$ amprolium hydrochloride (actual ingested dose $103.8 \pm 11.9 \mathrm{ppm}$ ) or clopidol (actual ingested dose $97.8 \pm 12.3 \mathrm{ppm}$ ) before exposure to theronts of Ichthyophthirius multifiliis significantly reduced the number of trophonts establishing in naïve fish by $62 \%$ ( $p<0.0001 \%$ ) and $35.2 \%$ ( $p<0.01 \%$ ) respectively (Expt 1, Table 2). A dose of 100 ppm salinomycin sodium (actual ingested dose $63.4 \pm 21.3 \mathrm{ppm}$ ) included in the fish feed reduced trophont numbers by $28.8 \%$, but not significantly so in this particular experiment. The trials with decoquinate, monensin and nicarbazin were not effective and were not tested further. Amprolium hydrochloride, clopidol and salinomycin were tested further to determine their efficacy as chemotherapeutants in fish already infected with I. multifiliis (Expt 2, Table 2). A dose of $75.2 \mathrm{ppm}$ amprolium hydrochloride administered for $10 \mathrm{~d}$ to infected fish brought about trophont reductions of $32.1 \%$ (Expt 2, Table 2). A repeat experiment whereby $62.8 \mathrm{ppm}$ amprolium hydrochloride was ingested brought about a $74.7 \%$ reduction in trophont numbers (Expt 3, Table 2). A dose of 92.2 ppm clopidol, however, gave only significant results in 1 of the 3 replicate tanks and a $20.1 \%$ reduction in trophont numbers across all tanks. Of the 3 compounds tested, salinomycin sodium appeared to be the most efficacious. When infected fish were given a nominal dose of $100 \mathrm{ppm}$, with an actual ingestion rate of $47.5 \mathrm{ppm}$, trophont numbers were significantly reduced by 93.4\% (Expt 2, Table 2). Repeat experiments feeding fish a dose of $100 \mathrm{ppm}$ (actual ingestion rates of 37.8 
Table 2. Oncorhynchus mykiss. Efficacy of each in-feed compound as a treatment for Ichthyophthirius multifiliis infection in flowthrough tank trials (except where stated otherwise). Regime, number of trophonts (mean \pm SD) for control and treated fish (number of fish), and statistical significance of results. ns: not significant; sig: significant (level of significance); T1-3: test tanks; C1-3: control tanks

\begin{tabular}{|c|c|c|c|c|}
\hline \multirow[t]{2}{*}{ Compound/regime } & \multirow{2}{*}{$\begin{array}{l}\text { Nominal dose } \\
\quad(\mathrm{ppm})\end{array}$} & \multicolumn{2}{|c|}{ No. of trophonts fish ${ }^{-1}(\mathrm{n})$} & \multirow[t]{2}{*}{ Significance } \\
\hline & & Test & Control & \\
\hline \multicolumn{5}{|c|}{ Expt 1: Feed (100 ppm) administered for 10 d prior to parasite exposure (static tank trials) } \\
\hline Amprolium hydrochloride & $103.81 \pm 11.92$ & $38.36 \pm 27.49(14)$ & $101.05 \pm 43.08(19)$ & Sig. $(p<0.0001)$ \\
\hline Clopidol & $97.82 \pm 12.27$ & $65.44 \pm 37.93(16)$ & & Sig. $(p<0.01)$ \\
\hline Decoquinate & $101.34 \pm 18.43$ & $97.90 \pm 36.26(14)$ & & ns \\
\hline Monensin & $72.57 \pm 25.72$ & $110.00 \pm 42.94(15)$ & & ns \\
\hline Nicarbazin & $96.08 \pm 46.22$ & $142.67 \pm 56.34(6)$ & & ns \\
\hline Salinomycin sodium & $63.41 \pm 21.30$ & $71.90 \pm 29.91(10)$ & & ns \\
\hline \multicolumn{5}{|c|}{ Expt 2: Feed (100 ppm) administered for $10 \mathrm{~d}$ after parasite exposure } \\
\hline $\begin{array}{r}\text { Amprolium hydrochloride } \\
\text { avg. }\end{array}$ & $\begin{aligned} & 70.20 \pm 20.86 \\
& 72.41 \pm 21.78 \\
& 82.91 \pm 19.83 \\
&=75.17 \pm 20.82\end{aligned}$ & $\begin{aligned} 19.40 & \pm 7.31(10) \\
35.13 & \pm 18.29(8) \\
152.00 & \pm 69.07(8)\end{aligned}$ & $\begin{aligned} 56.13 & \pm 29.35(8) \\
79.50 & \pm 24.64(10) \\
168.30 & \pm 48.09(10)\end{aligned}$ & $\begin{array}{l}\text { Sig. (T1 vs } C 2 p<0.05 \\
\text { T1 vs C3 } p<0.001 \text { ) }\end{array}$ \\
\hline avg. & $\begin{array}{r}95.54 \pm 33.57 \\
83.14 \pm 28.08 \\
98.03 \pm 31.67 \\
=92.24 \pm 31.11\end{array}$ & $\begin{aligned} 29.63 & \pm 26.15(8) \\
57.40 & \pm 18.53(10) \\
155.78 & \pm 66.01(8)\end{aligned}$ & $\begin{aligned} 56.13 & \pm 29.35(8) \\
79.50 & \pm 24.64(10) \\
168.30 & \pm 48.09(10)\end{aligned}$ & Sig. (T1 vs C3 $p<0.01$ ) \\
\hline Salinomycin sodium & $\begin{aligned} & 48.05 \pm 9.21 \\
& 55.52 \pm 6.35 \\
& 38.88 \pm 25.37 \\
= & 47.48 \pm 13.64(100)\end{aligned}$ & $\begin{aligned} 1.25 & \pm 1.39(8) \\
5.86 & \pm 3.31(8) \\
13.00 & \pm 10.38(9)\end{aligned}$ & $\begin{aligned} 56.13 & \pm 29.35(8) \\
79.50 & \pm 24.64(10) \\
168.30 & \pm 48.09(10)\end{aligned}$ & $\begin{array}{l}\text { Sig. (T1 vs } C 1 p<0.01, T 1 \\
\text { vs } C 2 p<0.001, T 1 \text { vs } C 3 \\
p<0.001, T 2 \text { vs } C 1 \\
p<0.05, T 2 \text { vs } C 2 p<0.01, \\
\text { T2 vs } C 3 p<0.001, \\
\text { T3 vs } C 2 p<0.001, \\
\text { T3 vs } C 3 p<0.001 \text { ) }\end{array}$ \\
\hline \multicolumn{5}{|c|}{ Expt 3: Dose and exposure as Expt 2} \\
\hline $\begin{array}{r}\text { Amprolium hydrochloride } \\
\text { avg. }\end{array}$ & $\begin{aligned} & 58.20 \pm 19.69 \\
& 67.40 \pm 20.27 \\
= & 62.80 \pm 19.7\end{aligned}$ & $\begin{array}{l}30.11 \pm 19.34(9) \\
22.67 \pm 9.21(9)\end{array}$ & $\begin{array}{l}105.40 \pm 63.07(15) \\
103.54 \pm 59.34(13)\end{array}$ & $\begin{array}{l}\text { Sig. (T1 vs C1 } p<0.001 \text {, } \\
\text { T1 vs } C 20 . p<0.001, T 2 \\
\text { vs } C 1 p<0.001, T 2 \text { vs } \\
\text { C2 } p<0.001 \text { ) }\end{array}$ \\
\hline \multicolumn{5}{|c|}{ Expt 4: Dose and exposure as Expt 2} \\
\hline Salinomycin sodium & $\begin{aligned} & 39.50 \pm 9.97 \\
& 36.30 \pm 13.23 \\
= & 37.80 \pm 11.60(100)\end{aligned}$ & $\begin{array}{r}4.40 \pm 3.30(10) \\
15.80 \pm 9.30(10)\end{array}$ & $\begin{array}{l}46.20 \pm 24.60(10) \\
55.70 \pm 18.20(10)\end{array}$ & $\begin{array}{l}\text { Sig. (T1 vs } \mathrm{C} 1 \mathrm{p}<0.01, \mathrm{~T} 1 \\
\text { vs } \mathrm{C} 2 \mathrm{p}<0.01, \mathrm{~T} 2 \text { vs } \mathrm{C} 2 \\
\mathrm{p}<0.05)\end{array}$ \\
\hline \multicolumn{5}{|c|}{ Expt 5: As Expt 2 but feed administered at dose of 50 or $100 \mathrm{ppm}$} \\
\hline $\begin{array}{l}\text { Salinomycin sodium } \\
\text { (50 ppm) avg. }\end{array}$ & $\begin{aligned} & 24.55 \pm 6.38 \\
& 24.65 \pm 6.59 \\
= & 24.60 \pm 6.50(50)\end{aligned}$ & $\begin{array}{l}33.70 \pm 24.40(10) \\
46.90 \pm 38.40(10)\end{array}$ & $\begin{array}{l}43.40 \pm 41.50(10) \\
53.20 \pm 26.00(10)\end{array}$ & ns \\
\hline $\begin{array}{l}\text { Salinomycin sodium } \\
\text { (100 ppm) }\end{array}$ & $\begin{aligned} & 41.71 \pm 8.04 \\
& 43.89 \pm 7.43 \\
= & 42.80 \pm 8.10(100)\end{aligned}$ & $\begin{aligned} 21.70 & \pm 16.50(10) \\
5.40 & \pm 4.40(10)\end{aligned}$ & $\begin{array}{l}43.40 \pm 41.50(10) \\
53.20 \pm 26.00(10)\end{array}$ & $\begin{array}{l}\text { Sig. (T1 vs C2 } p<0.01, T 2 \\
\text { vs } C 2 p<0.001)\end{array}$ \\
\hline \multicolumn{5}{|c|}{ Expt 6: As Expt 2 but feed administered for $5 d$ after parasite exposure } \\
\hline $\begin{array}{l}\text { Salinomycin sodium } \\
\\
\\
\text { avg. }\end{array}$ & $\begin{aligned} & 46.40 \pm 13.37 \\
& 40.60 \pm 5.56 \\
= & 43.10 \pm 9.50(100)\end{aligned}$ & $\begin{array}{l}30.00 \pm 29.00(10) \\
69.40 \pm 62.00(10)\end{array}$ & $\begin{array}{l}37.00 \pm 18.20(10) \\
12.10 \pm 18.60(10)\end{array}$ & ns \\
\hline
\end{tabular}

and $42.8 \mathrm{ppm}$ ) also significantly reduced trophont numbers by 80.2 and $72 \%$ respectively (Expts 4 and 5 , Table 2). As the experimental fingerlings within this trial showed palatability problems with salinomycin sodium, a lower nominal dose of 50 ppm was tested (Expt 5, Table 2). The palatability problems remained, and the actual dose taken up by the fish was only $24.6 \mathrm{ppm}$; there was no significant difference in the number of trophonts between those receiving medicated feed and the control group. A further trial was carried out in which medicated feed was fed for only $5 \mathrm{~d}$ at a nominal dose of $100 \mathrm{ppm}$ (Expt 6, Table 2). The 
actual ingestion rate was $43.1 \mathrm{ppm}$, but there was no significant difference between the test and control groups. These results indicate that salinomycin sodium is an effective treatment for $I$. multifiliis when given at the nominal dose of $100 \mathrm{ppm}$ for $10 \mathrm{~d}$.

\section{DISCUSSION}

Of the 6 in-feed compounds tested, the trials conducted with amprolium hydrochloride and clopidol (Expts 1 to 3) showed some protection against subsequent exposure to theronts of Ichthyophthirius multifiliis (Table 2). The period of protection provided by these compounds is unknown, and is worthy of further investigation. If the protection is long-lasting then these compounds could have their place in a management control strategy whereby they could be administered to farm stock prior to periods of high infection or prolonged elevation of water temperature. It is more often the case, however, that treatments are not given until the white spots or trophonts are detected on the fish. Thus it is imperative to have efficacious chemicals that are able to kill the trophonts intra-epithelially. In-feed treatments with amprolium hydrochloride or clopidol for $10 \mathrm{~d}$ in fish already infected with I. multifiliis had significant results, reducing trophont numbers by 32.1 to 74.7 and $20.1 \%$ respectively. The best results, however, were obtained with salinomycin sodium, with doses ranging from 37.8 to $47.5 \mathrm{ppm}$ reducing trophont numbers by 72 to $93.4 \%$. The target inclusion rate of $100 \mathrm{ppm}$ for $10 \mathrm{~d}$ appears to be quite critical for this compound, as lower target doses of medicated feed (nominal dose of $50 \mathrm{ppm}=24.6 \pm 6.5 \mathrm{ppm}$ actual ingested dose) or shorter periods of administration (5 d) resulted in a lower removal of trophonts. Despite the efficacy of salinomycin sodium as an anti-coccidial substance that causes parasite death through mitochondrial and metabolic disturbance as a consequence of increased membrane permeability and osmotic disruption, poultry receiving medicated feed (doses of 60 to $180 \mathrm{ppm}$ ) were reported to have lower mean body weights than control groups (Rizvi \& Anjum 1999), suggesting unpalatability of this drug.

Data relating to the retention of these drugs within body tissues derive primarily from studies conducted within the poultry industry. Atef et al. (1993) administered a single dose of salinomycin orally to chickens

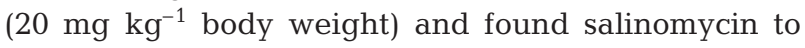
have a half-life of $3.64 \mathrm{~h}$ and an elimination half-life of $1.96 \mathrm{~h}$. After $48 \mathrm{~h}$, no salinomycin residues were detected in tissues except in the liver, but these had disappeared completely $72 \mathrm{~h}$ after administration of the drug. In a similar study by Hamamoto et al. (2000), chickens in both a fasted and a non-fasted condition were fed a diet containing either 13 or $26 \mathrm{mg} \mathrm{kg}^{-1}$ amprolium hydrochloride. Amprolium residues in plasma samples taken from the sub-wing vein indicated that the elimination half-life after oral administration was 0.292 to $0.654 \mathrm{~h}$. Oishi (1991) fed chickens a medicated feed containing $1 \mathrm{ppm}$ clopidol for $10 \mathrm{~d}$. Clopidol at an average level of $0.036 \mathrm{ppm}$ was detected in the eggs throughout the course of treatment, and was no longer detectable $3 \mathrm{~d}$ after the chickens returned to an unmedicated diet. Given that the activity of these drugs is the same in trout, to maximise exposure of the parasite to the drug, fish are therefore best treated after infection with Ichthyophthirius multifiliis. A course of medicated feed prior to periods of high parasite exposure would therefore confer little protection, unless continued, since the drugs are rapidly metabolised and eliminated from the body.

The number of potentially efficacious compounds for Ichthyophthirius multifiliis is possibly being underestimated because either the screening methodology used by some studies is inappropriate or because a chemical is rejected as it failed to eradicate all stages of the parasite. Considering the relative ineffectiveness of the chemicals presently permitted for the treatment of I. multifiliis, chemicals that achieve significant reductions in the number of surviving trophonts are certainly of value. Although, under the regimes tested here, salinomycin sodium does not completely eradicate infection, it is still of great potential value as a treatment within a programme of management control. If therapy leads to the survival of fish exposed to a first infection of I. multifiliis, then an acquired immunity could provide subsequent protection (up to $8 \mathrm{mo}$, Hines \& Spira 1974) against further infection in an environment of continual exposure.

A study by Tojo \& Santamarina (1999), screening potential chemotherapeutants for use against Ichthyobodo necator, demonstrated the efficacy of 3 promising candidates, metronidazole, secnidazole, triclabendazole. Subsequently, Tojo-Rodriguez \& SantamarinaFernandez (2001) tested metronidazole and secnidazole against Ichthyophthirius multifiliis, whereby efficacy was assessed by trophont counts in skin scrapes. Because no one chemical completely eradicated trophonts, these authors concluded that neither of these compounds was efficacious. A closer look at the latter data set shows that $35 \%$ of the fish (20 per test group) tested with metronidazole and $75 \%$ of the fish tested with secnidazole were free of trophonts compared to $5 \%$ of fish in the control group. Their methodology makes it difficult to assess the true value of these compounds, and they should therefore be retested taking trophont counts from the whole body and gills.

This study has demonstrated the efficacy of a $10 \mathrm{~d}$ course of medicated feed containing salinomycin in 
reducing the number of surviving trophonts on experimentally infected fish by 72 to $93.4 \%$. The protection offered to fish by this compound in their feed remains to be established. It would be worthwhile to determine if the results could be improved upon by using salinomycin in combination with other anti-coccidiostats in a shuttle program, as has been successfully done in the poultry industry.

Acknowledgements. The authors would like to thank Dr. Julian Braidwood and Richard Hunter of Vericore Limited, Gordon Rae of Scottish Quality Salmon, the British Trout Association and in particular Mark Davies and Peter Routledge, and the various fish farms that were visited throughout the course of this study for their valuable input and assistance. This study (TRT06) was funded by a DEFRA LINK Aquaculture award to R. Wootten and C. Sommerville.

\section{LITERATURE CITED}

Anonymous (1995) EC bans the use of dimetridazole in food animals. Vet Rec 137:230

Arakawa A, Tanaka Y, Baba E, Fukata T (1991) Effects of clopidol on sporulation and infectivity of oocysts. Vet Parasitol 38:55-60

Armson A, Meloni BP, Reynoldson JA, Thompson RCA (1999) Assessment of drugs against Cryptosporidium parvum using a simple in vitro screening method. FEMS Microbiol Lett 178:227-233

Atef M, Ramadan A, Youssef SAH, Elsooud KA (1993) Kinetic disposition, systemic bioavailability and tissue distribution of salinomycin in chickens. Res Vet Sci 54:179-183

Bolder NM, Wagenaar JA, Putirulan FF, Veldman KT, Sommer M (1999) The effect of flavophospholipol $\left(\right.$ Flavomycin ${ }^{\circledR}$ ) and salinomycin sodium $\left(\operatorname{Sacox}^{\circledR}\right)$ on the excretion of Clostidium perfringens, Salmonella enteritidis, and Campylobacter jejuni in broilers after experimental infection. Poult Sci 78:1681-1689

Buxton D, Brebner J, Wright S, Maley SW, Thomson KM, Millard K (1996) Decoquinate and the control of experimental ovine toxoplasmosis. Vet Rec 138:434-436

Daugschies A, Gasslein U, Rommel M (1998) Comparative efficacy of anticoccidials under the conditions of commer-

Editorial responsibility: Wolfgang Körting,

Hannover, Germany cial broiler production and in battery trials. Vet Parasitol 76:163-171

Dohle A, Schmahl G, Raether W, Schmidt H, Ritter G (2002) Effects of orally administered chemotherapeutics (quinine, salinomycin) against Henneguya sp. Thelohán, 1892 (Myxozoa: Myxobolidae), a gill parasite in the tapir fish Gnathonemus petersii Günther, 1862 (Teleostei). Parasitol Res 88:1-10

Hamamoto K, Koike R, Machida Y (2000) Bioavailability of amprolium in fasting and non-fasting chickens after intravenous and oral administration. J Vet Pharmacol Ther 23: 9-14

Hines RS, Spira DT (1974) Ichthyophthiriasis in the mirror carp Cyprinus carpio L. V. Acquired immunity. J Fish Biol 6:373-378

MacIntire DK, Vincent-Johnson NA, Kane CW, Lindsay DS, Blagburn BL, Dillon AR (2001) Treatment of dogs infected with Hepatozoon americanum: 53 cases (1989-1998). J Am Vet Med Assoc 218:77-82

Matthews RA (1994) Ichthyophthirius multifliis Fouquet, 1876: infection and protective response within the fish host. In: Pike AW, Lewis JW (eds) Parasitic diseases of fish. Samara Publishing Limited, Dyfed, p 17-42

Oishi Y (1991) Studies on residues of clopidol and comparison with residues of nicarbazin in eggs of laying hens. J Food Hyg Soc Jpn 32:8-12

Peeters JE, Derijcke J, Verlinden M, Wyffels R (1994) Sensitivity of avian Eimeria spp. to 7 chemical and 5 ionophore anticoccidials in 5 Belgian integrated broiler operations. Avian Dis 38:483-493

Rizvi F, Anjum AD (1999) Effect of salinomycin on broiler health. Vet Arh 69:39-47

Tojo JL, Santamarina MT (1999) Oral pharmacological treatments for parasitic diseases of rainbow trout (Oncorhynchus mykiss). III. Ichthyobodo necator. Dis Aquat Org 33:195-199

Tojo Rodriguez JL, Santamarina Fernandez MT (2001) Attempts at oral pharmacological treatment of Ichthyophthirius multifiliis in rainbow trout, Oncorhynchus mykiss (Walbaum). J Fish Dis 24:249-252

Traxler GS, Richard J, McDonald TE (1998) Ichthyophthirius multifiliis (Ich) epizootics in spawning sockeye salmon in British Columbia, Canada. J Aquat Anim Health 10: 143-151

Valtonen ET, Keranen AL (1981) Ichthyophthiriasis of Atlantic salmon, Salmo salar L., at the Montta hatchery in northern Finland in 1978-1979. J Fish Dis 4:405-411

Submitted: August 8, 2002; Accepted: December 12, 2002 Proofs received from author(s): April 22, 2003 